\title{
Sistem Informasi Penerimaan Order Produksi Pakaian pada Yoshida
}

\author{
Edy Purwanto' ${ }^{1}$, Ade Mubarok, M. Kom² \\ ${ }^{1,2}$ Universitas Adhirajasa Reswara Sanjaya \\ e-mail: ${ }^{1}$ edy.aja94@gmail.com, ${ }^{2}$ adem@ars.ac.id

\begin{tabular}{ccc}
\hline Diterima & Direvisi & Disetujui \\
$27-09-2020$ & $09-11-2020$ & $12-12-2020$ \\
\hline
\end{tabular}

\begin{abstract}
Abstrak - Pada perkembangan teknologi sistem informasi pada yoshida dalam penerimaan order produksi pakaian yang dibuat dengan sistem terkomputerisasi agar dapat pencatatan laporan seperti laporan pelanggan, gudang, stok barang, laporan hari, laporan perbulan serta pencatatan laporan pertahun dan pembelian barang dapat membantu suatu pekerjaan agar terkomputerasi Penyimpanan data mengunakan Mysql agar dapat membangun sistem untuk perancangan sistem informasi. Untuk pembangunan sistem yang akan digunakan dengan metode air terjun (waterfall), pendekatan pengembangan perangkat lunak dimulai dari kebutuan pengguna lalu berlanjut melalui tahapan perencanaan, yang diakiri menjadi perangkat lunak. Bahan yang akan digunakan dari pembangunan sistem mengunakan UML dan Bahasa pemograman Laravel. Untuk mempermudah pelanggan dan admin dalam melakukan proses pekerjaan dalam sistem pemesanan dan sistem penjualan barang ini menjadi lebih cepat dan memudahkan pelanggan untuk melakukan transaksi. Dengan perkembangan dan informasi untuk penyimpanan data atau yang disebut database pada YOSHIDA, dapat memunculkan pelayanan produksi baru dengan mudah dan efisien, dan juga mempermuda mengontrol pemesanan barang dalam jumlah besar dengan menggunakan data MySQL. Mempermudah melakukan komunikasi dengan pelanggan dan melakukan transaksi kapanpun dan dimanapun.
\end{abstract}

Kata Kunci : Penerimaan Order YOSHIDA, MySQL, Laravel.

\begin{abstract}
In the development of information system technology in Yoshida, in receiving clothing production orders made with a computerized system to record reports such as customer reports, warehouse, stock of goods, day reports, monthly reports and annual reports and purchases of goods can help a job become computerized Data storage using Mysql to build systems for information system design. For designing the system that will be used with the waterfall method. The software development approach starts from the needs of the user and then continues through the planning stage, which ends in software. Materials to be used from system development using UML and the Laravel programming language. To make it easier for customers and admins to carry out work processes on the ordering system and the sales system for this item, it becomes faster and makes it easier for customers to make transactions. With the development and information for data storage or what is called a database at YOSHIDA, it can create new production services easily and efficiently, and also makes it easier to control large orders of goods using Mysql data. Make it easier to communicate with customers and make transactions anytime and anywhere.
\end{abstract}

Keywords: Receipt of YOSHIDA Orders, MySQL, Laravel.

\section{PENDAHULUAN}

Dengan adanya perkembangan teknologi sistem informasi banyaknya sumber daya manusia ( SDM ) yang mencari informasi tentang produksi pakaian hal ini untuk permudah pekerjaan dan meningkatkan produksi di suatu perusahaan produksi pakaian YOSHIDA.

Teknologi informasi memiliki pengaruh yang besar pada kehidupan manusia dengan teknologi informasi, manusia dapat memudahkan pekerjaan atau mencari suatu produk diinginkan. Dengan manfaat teknologi sistem informasi memiliki sangat penting kepada para pengguna untuk menginformasikan atau mencari informasi yang sangat memuaskan dalam artian memudahkan suatu pekerjan. Teknologi Sistem informasi dapat menciptakan efektifitas dan keselarasan kinerja dalam suatu perusahaan (Irawan et al., 2017).

Dengan ini penulis ingin melakukan penelitian pada perusahaan YOSHIDA . Oleh karena itu manajemen dalam penerimaan order produksi pakaian yang dibuat dengan sistem terkomputerisasi agar dapat pencatatan laporan seperti laporan pelanggan, gudang, stok barang, laporan hari, laporan perbulan serta pencatatan laporan pertahun 
dan pembelian barang dapat membantu suatu pekerjaan (Abdulloh et al., 2019)

Dengan itu penulis mengarahkan komputerisasi berbasis online demi kenyamanan owner maupun pelanggan serta untuk menjawab tantangan sebagai perusahaan pemenang dalam meraih sebanyak mungkin pelanggan dalam kegiatan bisnisnya (Irawan et al., 2017).

Dari permasalahan tersebut dibutuhkan sistem informasi berbasis web untuk memberikan kemudahan pihak YOSHIDA dalam melakukan pekerjaan. Penulis bertujuan untuk melakukan penelitian dengan judul "Sistem Informasi Penerimaan Order Produksi pada YOSHIDA".

Dengan perbaikan struktur organisasi, melakukan perancangan yang baru, aktivitas desain produk yang lebih efisien dapat memberikan pekerjan produksi yang lebih cepat dan fleksibel, yang akan lebih terkendali, dan aktivitas perhitungan biaya produksi lebih akurat dan untuk mengembangkan sebuah sistem penerimaan order produksi pakaian (Sihombing et al., 2016) yang dapat meningkatkan pekerjaan di perusahaan YOSHIDA.

Dengan perkembangan teknologi informasi untuk penyimpanan data atau disebut database dapat penyimpanan banyak. Untuk itu penulis berkesimpulan penyimpanan data mengunakan Mysqluntuk pendekatan pengembangan perangkat lunak, dengan kebutuhan pengguna melalui tahapantahapan analis, yang akan diakhiri menjadi perangkat lunak. Untuk perancangan sistem informasi. Pembangunan sistem yang akan digunakan oleh penulis dengan menggunakan metode air terjun ( waterfall ), Dan bahan yang akan digunakan dari pembangunan sistem mengunakan Bahasa pemograman dan UML, sedangkan untuk pembutan sistem adalah sublime text, xampp, framework, bootstrap dan photoshop yang akan digunakan pembuatan sistem informasi.

\section{Landasan Teori}

a. Sistem Informasi

Menurut Robert A. Leitch \& K. Roscoe Davis dalam kesimpulan (Solihin \& Nusa, 2017) Sistem informasi merupakan suatu jaringan sistem variabel yang terorganisir didalam organisasi, yang mempertemukan kebutuhan dalam pengolahan transaksi dan mendukung kegiatan-kegiatan suatu organisasi atau menyediakan sebuah laporan yang diperlukan.

b. PHP

Menurut Setiawan dalam (Mediana \& Nurhidayat, 2018) bahwa "PHP merupakan kependekan dari Hypertext Preprocessor yang merupakan sebuah bahasa script tingkat tinggi yang dipasangan pada dokumen $H T M L "$.

\section{c. XAMPP}

$X A M P$ merupakan sebuah perangkat lunak gratis yang bebas digunakan untuk keperluanserveryang terdiri dari (localhost)Apache HTTP Server, MySQL database dan (Mediana \& Nurhidayat, 2018).

\section{d. Pengertian Bootstrap}

Bootstrapmerupakan aplikasi web yang lebih cepat dan mudah unt suatu pengembangan sebuah sistem yang akan di banguan (Mediana \& Nurhidayat, 2018).

\section{e. UML \\ 1) Use Case Diagram}

Use case diagram menggambarkan aktor-aktor yang diharapkan pada fungsinya dari sebuah sistem. Pebuatan sistem, pada Sebuah use case dapat merepresentasikan antara sebuah interaksi dan aktor dengan sistem. Use casemelihatkan kegiatan kegiatan sebuah pekerjaan, seperti login ke sistem, menginput data dan sebagainya. Seorang aktor unuk sebuah pekerjaan-pekerjaan manusia dan mesin yang saling berinteraksi yang dituju (Dharwiyanti \& Wahono, 2003).

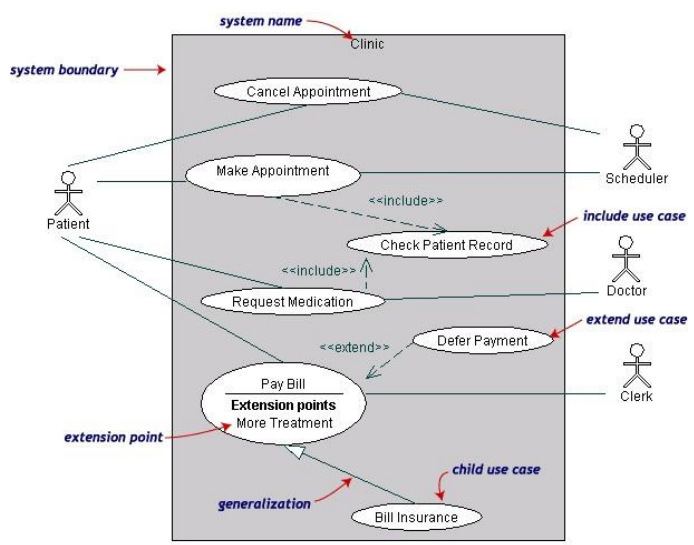

Sumber: (Dharwiyanti \& Wahono, 2003).

\section{2) Class Diagram}

Gambar UseCase Diagram

Class diagram merupakan suatu sebuah atribut yang dapat menghasilkan suatu objek yang saling berkaitan satu sama lainuntuk pengembangan sistem yang akan dibangun. Class diagram dapat menggambarkan struktur- struktur dan deskripsi class objek. (Dharwiyanti \& Wahono, 2003).

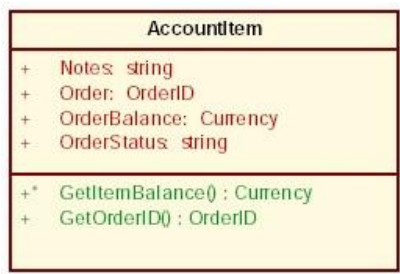

Sumber: (Dharwiyanti \& Wahono, 2003).

Gambar Class Diagram 


\section{3) Activity Diagram}

Aktivity diagram merupakan suatu struktur alur aktiviats atau proses aliran data yang dapat menghasilkan sistem informasi pada sebuah sistem yang dibangun untuk menggambarkan proses proses yang terjadi.

Oleh karena itu activity diagram tidak menggambarkan behaviour, tetapi lebih menggambarkan proses-proses interaksi antar sistem(Dharwiyanti \& Wahono, 2003).

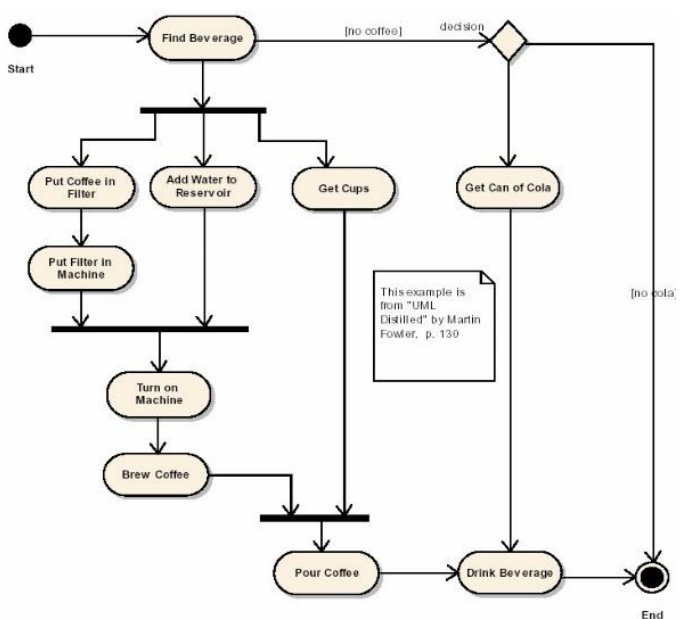

Sumber: (Dharwiyanti \& Wahono, 2003).

\section{f. Laravel}

\section{Gambar Activity Diagram}

Menurut Naista dalam (Hanafri \& Luthfiudin, 2018) bahwa pengertian framework adalah suatu kerangka yang terstruktur pada umumnya wadah atau tempat sistem. konseptual dasar yang digunakan dalam memecahkan dan menangani suatu masalah pada wadah atau kerangka kerja dari suatu website yang akan dirancang untuk pembangunan sebauah aplikasi. Dengan memakai kerangka tersebut pembuatan program dan memudahakan suatu pekerjaan dan waktu yang digunakan untuk membuat website dapat lebih singkat dan memudahkan dalam perbaikan.

Dalam penggunaanya laravel mempunyai beberapa kekurangan diantaranya yaitu ukuran file terlalu besar. Laravel terdapat sebuah file yang bersifat default seperti vendor. Selain itu, Laravel dibutuhkan koneksi ke internet untuk menginstalasi dan mengunduh library laravel.

\section{g. Metode Pengembangan}

Metode pengembangan yang digunakan pada penelitian ini adalah metode Waterfall. Pada tahapan ini yang dilakukan pada metode Waterfall Menurut Jogiyanto dalam (Subianto, 2019) bahwa pengembangan sistem dapat didefinisikan suatu aktivitas pengembangan untuk menghasilkan sebuah sistem informasi berbasis komputer yang dapat menyelesaikan persoalan organisasi atau memanfaatkan kesempatan yang timbul. Metode pengembangan sistem yang digunakan oleh adalah metode waterfall.

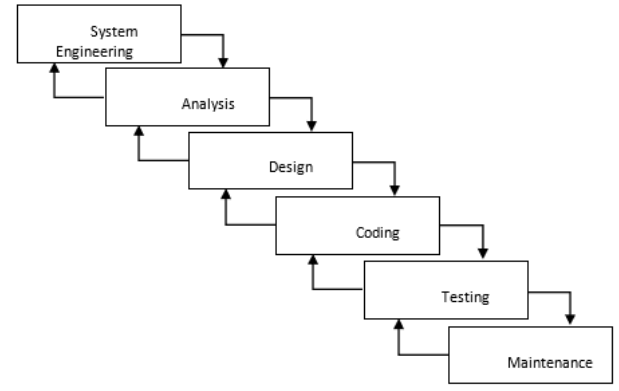

Sumber: (Subianto, 2019).

\section{Gambar Waterfall}

Pengertian Bahan Baku

Di suatu perusahaan Bahan baku merupakan bahan untuk dipergunakan pada proses produksi dengan periode yang bersangkutan dan yang akan menjadi penolong untuk memiliki peran penting pada proses produksi (Haryana et al., 2017).

h. Usaha Kecil, Mikro dan Menengah

Berdasarkan Undang-Undang Nomor 20 Tahun 2008 tentang Usaha Mikro, Kecil dan Menengah dalam pasal 3 disebutkan bahwa usaha mikro bertujuan menumbuhkan dan mengembangkan usahanya dalam rangka membangun perekonomian nasional berdasarkan ekonomi yang berkeadilan (Prasetyo et al., 2018). Ada perbedaan tentang usaha mikro, kecil, dan menengah yaitu;

1) Usaha Mikro

UMKM (Usaha Menengah Kecil dan Mikro) berdasarkan Undang Undang Nomor 20 Tahun 2008 tentang adalah suatu usaha produktif yang memilik badan usaha perorangan untuk memenuhi kriteria Usaha Mikro (Prasetyo et al., 2018).

2) Usaha Kecil

kriteria Usaha Kecil pada ekonomi produktif yang berdiri sendiri, oleh badan usaha yang bukan bukan dari cabang perusahaan atau menjadi bagian langsung maupun tidak langsung dari usaha menengah (Prasetyo et al., 2018).

\section{3) Usaha Menengah}

usaha ekonomi produktif yang berdiri sendiri, yang hasil penjualan tahunan sebagaimana diatur dalam Undang-Undang dilakukan oleh orang perseorangan atau badan usaha yang bukan merupakan anak perusahaan cabang yang dimiliki, dikuasai atau menjadi bagian baik langsung maupun tidak langsung dengan Usaha Kecil atau usaha besar dengan jumlah kekayaan bersih (Prasetyo et al., 2018). 
4) Usaha mikro

Salah satu utama ekonomi nasional yang medapatkan kesempatan utama, dukungan, perlindungan serta pengembangan kepada kelompok usaha ekonomi tanpa harus mengabaikan usaha besar dan badan usaha milik pemerintah maka usaha miko merupakan usaha yang dapat memperluas lapangan pekerjaan serta memberikan pelayanan ekonomi kepada masyarakat untuk dapat berperan dalam proses pemerataan dan peningkatan pendapatan masyarakat dan mendorong pertumbuhan ekonomi, (Prasetyo et al., 2018).

Menurut Departemen Tenaga Kerja (Depnaker) usaha mikro adalah usaha yang memiliki kurang dari 5 orang tenaga kerja (Prasetyo et al., 2018).

\section{METODE PENELITIAN}

1. Sejarah Perusahaan

Sejarah singkat perusahaan YOSHIDA didirikan pada tahun 1998, YOSHIDA adalah salah satu perusahaan produksi dan penjualan baju anak yang beralamat di jl. Jend Sudirman, No.316, Ciroyom, Kec. Andir, Kota Bandung, Jawa Barat 40182 yang berada di atas Gedung bengkel Raja Ban DUNLOP di lt.2.

Perusahaan YOSHIDA pada saat ini dalam manajemen dan penerimaan order produksi pakaian yang belum tersistem komputerisasi untuk pencatatan laporan seperti laporan -laporan yang dibutuhkan.

\section{Desain penelitian}

Dalam penelitian ini penulis melakukan perumusan masalah yang telah didesain dengan activity diagram berjalan seperti gambar berikut yang sudah desain sedemikian rupa oleh peneliti :

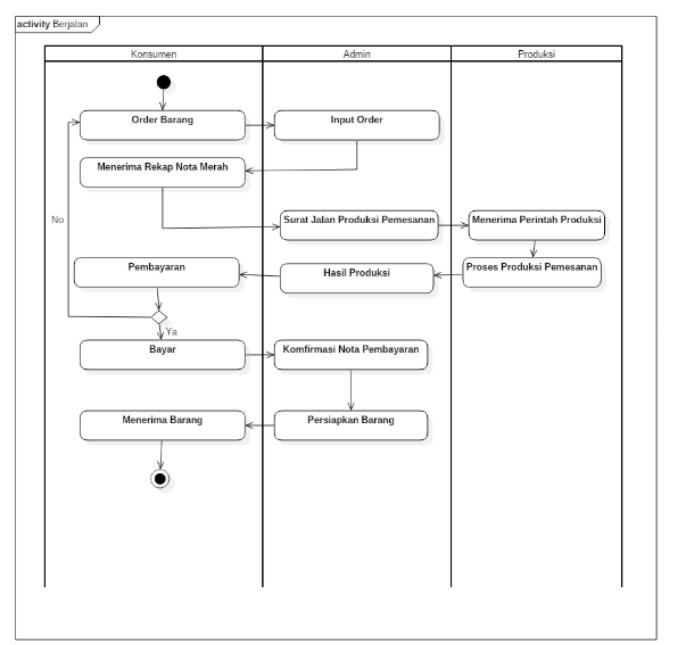

Gambar Activity Berjalan.
3. Metode Pengmpulan data

Dengan adanya kerangka kerja dapat mempermudah penelitian pada Yoshida Sebagai Tahap dan pungsinya dalam pengumpulan data yang digunakan dalam penelitian ini adalah :

a. Observasi

Obsevasi merupakan suatu metode pengumpulan data yang digunakan dengan pengamatan yang disertakkan pencatatan, keadaan, atau perilaku objek sasaran. Tujuan dari observasi adalah untuk mendiskripsikan kegiatan yang terjadi oleh orang yang terlibat.

\section{b. Wawancara}

Wawancara merupakan metode pengumpulan data yang di proses oleh pewawancara yang akan diwawancarai.

c. Literatur

Literarur adalah teknik penyusunan untuk memudahkan langkah-langkah yang akan diambil oleh penulis dalam penelitian Seperti jurnal dan buku.

\section{Kebutuhan System}

1) Analisis Kebutuhan Pengguna

untuk mengetahui fungsi kebutuhan dari pengguna yang berhubungan langsung dengan sistem tersebut terbagi menjadi beberapa bagian yaitu sebagai Owner, admin

5. Kebutuhan Non Fungsional

Kebutuhannonfungsional untuk mengetahui spesifikasi kebutuhan system melibatkananalisisperangkatkeras/hardware, analisisp erangkat lunak/software, analisis pengguna/user.

\section{HASIL DAN PEMBAHASAN}

1. Sistem Yang Diusulkan

Sistem Informasi Pelayanan pada YOSHIDA yang diusulkan berharap dapat memberikan gambaran yang jelas dalam pembuatan sistem informasi, dapat membantu proses penerimaan order dan memperluas pelanggan YOSHIDA. Analisa sistem yang diusulkan digambarkan dengan aktivity diagram yang dapat menjelaskan proses aliran data sehingga dapat menghasilkan sistem informasi yang diinginkan. Adapun kegiatan-kegitan gambar sebagai berikut : 


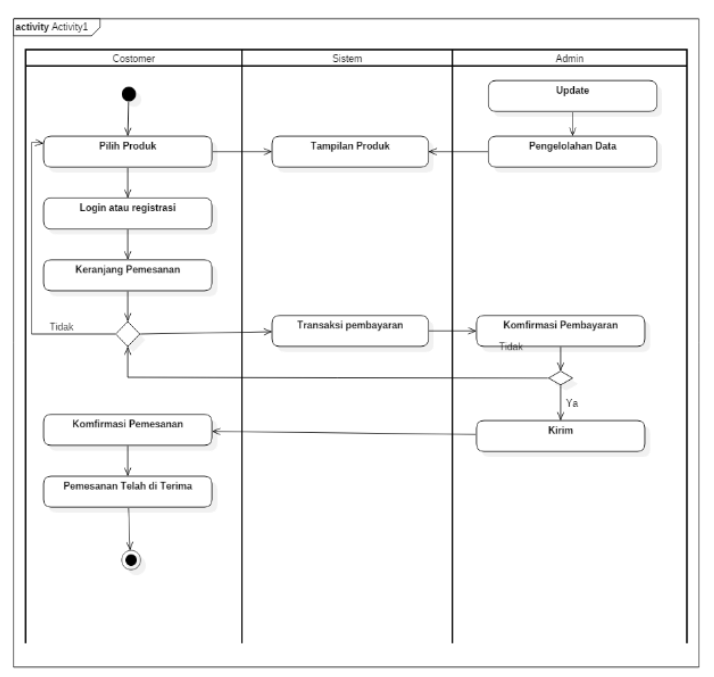

Gambar Sistem diusulkan.

a. Use Case Diagram

Pancangan Use Case Diagram Sistem Informasi Pelayanan pemesanan order produksi pada YOSHIDA dapat dilihat pada gambar sebagai berikut ini:

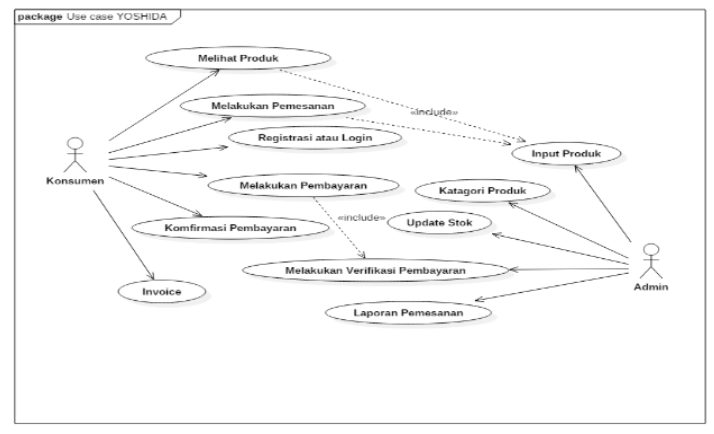

b. Class Diagram

Gambar UseCase Diagram.

Perancangan Class Diagram Sistem Informasi Pelayanan pemesanan order produksi pada YOSHIDA dapat dilihat pada gambar sebagai berikut ini:

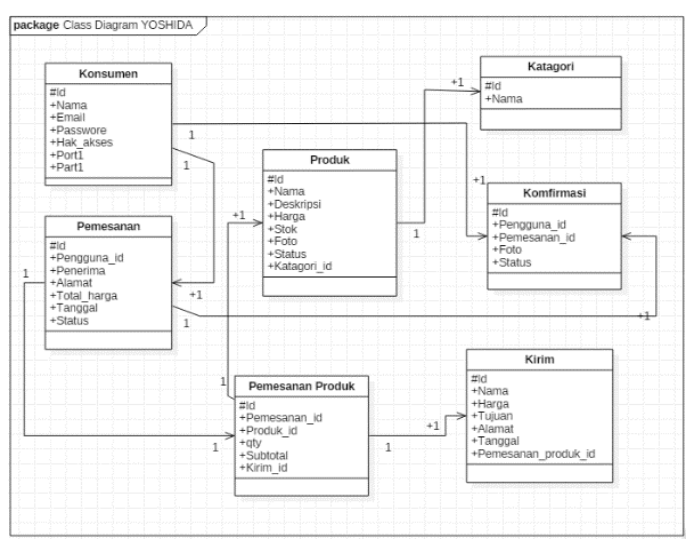

\section{Implementasi}

Tahap implementasi Sistem Informasi Pelayanan penerimaan order produksi pada YOSHIDA merupakan proses yang dilakukan setelah tahap perancangan sistem yang sudah selesai dilaksanakan. Dalam tujuan untuk dicapainya pada suatu tahap ini adalah dapat dioperasikan hasil perancangan Sistem Informasi Pelayanan penerimaan order produksi pada YOSHIDA yang telah dibuat. Dengan adanya tahapan perancangan dijelaskan mengenai sistem yang sudah dirancang sedemikian rupa dan bagaimana cara penggunaannya untuk para pengguna.

a. Halaman Login

Halaman Login digunakan untuk autentikasi pengguna Sistem Informasi, apakah adminstrator atau pengguna.

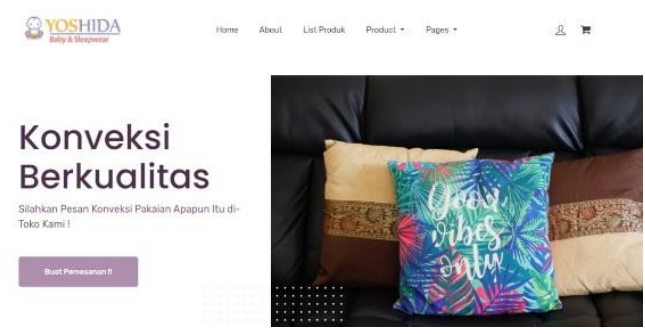

Gambar Halaman Login.

b. Halaman Admin

Halaman Admin adalah halaman yang pertama kali muncul pada saat admin berhasil masuk ke dalam sistem.
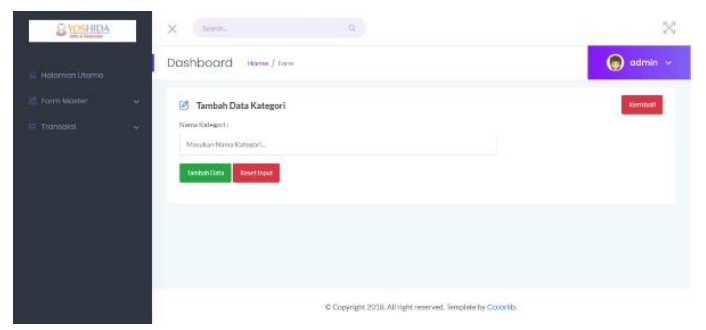

Gambar Halaman Admin.

c. Halaman Kategori Produk

Berikut ini merupakan data-data kategori produk pada Sistem Informasi Pelayanan penerimaan order produksi pada YOSHIDA. Halaman kategori produk dapat dilihat pada gambar sebagai berikut ini:

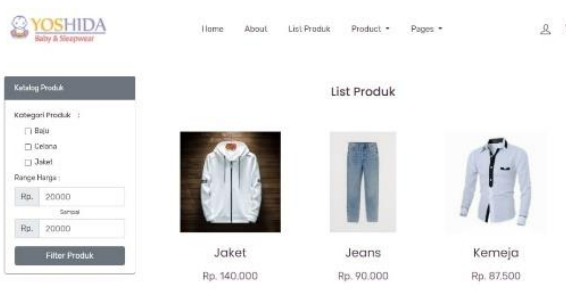

Gambar Class Diagram.

Gambar Halaman Kategori Produk. 


\section{Testing}

Untuk tahap testingpenguji menggunakan Metode Black Box testing, Metode Black Box yang digunakan untuk mengtes atau mengukur program kompleksitas dari desain proseduraldan kebutuhan fungsi dari suatu program.

\section{KESIMPULAN}

Berdasarkan hasil yang diperoleh dari pembahasan aplikasi pada Sistem Informasi Pelayanan penerimaan order produksi pada YOSHIDA, maka dapat diambil beberapa kesimpulan sebagai berikut :

1. Dengan perkembangan teknologi informasi untuk penyimpanan data atau disebut database dapat penyimpanan banyak. Dengan data mengunakan Mysql agar dapat sistem informasi pelayanan penerimaan order produksi pada YOSHIDA yang baru.

2. Sistem pemesanan dan sistem penjualan barang ini menjadi lebih mudah untuk mempercepat dan memudahkan pelanggan untuk melakukan transaksi.

\section{REFERENSI}

Abdulloh, Studi, P., Informatika, T., \& Ardian, N. (2019). RANCANG BANGUN SISTEM INFORMASI PENJUALAN PAKAIAN BERBASIS WEB (Studi Kasus Distro Authezz Yogyakarta). 3(1).

Dharwiyanti, S., \& Wahono, R. S. (2003). Pengantar Unified Modeling LAnguage (UML). IlmuKomputer.Com, 1-13. http://www.unej.ac.id/pdf/yanti-uml.pdf

Hanafri, M. I., \& Luthfiudin, I. (2018). Rancang Bangun Sistem Monitoring Kehadiran Dosen Berbasis Web Pada STMIK Bina Sarana Global. 8(1).

Haryana, A., Rochman, A., \& Setyaningsih, A.
(2017). Perancangan sistem informasi perencanaan dan pengendalian bahan baku pada home industri. Jurnal Sisfotek Global, $7(1)$, 87-95. http://journal.stmikglobal.ac.id/index.php/sisfo tek/article/view/120

Irawan, A., Risa, M., Muttaqien, M. A., \& Shinnay, A. E. (2017). Perancangan Sistem Informasi Penjualan Pakaian Pada CV Nonninth Inc Berbasis Online. POSITIF : Jurnal Sistem Dan Teknologi Informasi, 3(2), 74. https://doi.org/10.31961/positif.v3i2.417

Mediana, D., \& Nurhidayat, A. (2018). Rancang Bangun Aplikasi Helpdesk ( a-Desk ) Berbasis Web Menggunakan Framework Laravel ( Studi Kasus Di Pdam Surya Sembada Kota Surabaya ). Jurnal Manajemen Informatika, 8(02), 75-81.

Prasetyo, D. W., Mojoagung, K., Jombang, K., \& Belah, K. (2018). Pembinaan Usaha Kecil Mikro dan Menengah (UMKM) Konveksi Desa Karobelah Kecamatan Mojoagung - Jombang. 2(1), 9-14.

Sihombing, D. O., Nugraha, W., \& Andani, F. (2016). Aplikasi Pengelolaan Data Order Mkios Berbasis Web Pada TDC PT. Telesindo Shop Pontianak. Daniel $O$. Sihombing, Wahyu Nugraha, Farida Andani, 129-138.

Solihin, H. H., \& Nusa, A. A. F. (2017). Rancang Bangun Sistem Informasi Penjualan, Pembelian dan Persedian Suku Cadang Pada Bengkel Tiga Putra Motor Garut. Jurnal Infotronik, Volume 2,(2), 107-115.

Subianto. (2019). Sistem informasi pemesanan pada bidang usaha jasa konveksi berbasis web. 109-115. 